\title{
Índices \\ Anales del Instituto de Investigaciones Estéticas núms. 73-76
}

Anales del Instituto de Investigaciones Estéticas, vol. Xx, núm. 73, otoño de 1998.

Artículos

Russo, Alessandra, "El renacimiento vegetal. Árboles de Jesé entre el Viejo M undo y el N uevo", pp. 5-4I, ils.

Báez Rubí, Linda, "D e harmonia mundi: ¿un reino de Saturno novohispano?", pp. $43-69$.

Alcántara Rojas, Berenice, “Fragmentos de una evangelización negada. U n 'ejemplo' en náhuatl de fray Ioan Baptista y una pintura mural del convento de Atlihuetzia", pp. 7I-87, ils.

Cuadriello, Jaime, "T resguerras, el sueño y la melancolía", pp. 89-I28, ils.

Velázquez Guadarrama, Angélica, "Castas o marchitas: 'El amor del colibrí' y 'La flor muerta' de M anuel de 0 caranza", pp. I29-I64, ils.

Dallal, Alberto, "Guillermo Keys Arenas: modelo en el desarrollo de la danza de concierto del siglo xx en M éxico. Los primeros años", pp. I65-188, ils.

O bras, documentos, noticias

Russo, Alessandra, "'Lenguaje de figuras y su entendimiento... ' Preparación de un estudio sobre los graffitis en los conventos de la época colonial", pp. I9I-I96, ils.

T orre Villar, Ernesto de la, "Un tesoro de la poesía novohispana”, pp. 197-210.

Rubial, Antonio, "Palabra e imagen. Un mural franciscano desaparecido en la Puebla del siglo XIX", pp. 2II-2I5.

Libros, reseñas

Bargellini, C lara, “Los canteros de la catedral de Sevilla, de Juan Clemente Rodríguez Estévez", p. 217. 
DOI: http://dx.doi.org/10.22201/iie.18703062e.2000.77.1938

290

ÍNDICES

N oelle, Louise, "Espacios distantes... Aún vivos. Las salas cinematográficas de la ciudad de M éxico, de Francisco H aroldo Alfaro Salazar y Alejandro O choa Vega", pp. 2I8-2I9.

H errera, Arnulfo, "El mundo simbólico. Serpientes y animales venenosos. Los insectos, de Filippo Picinelli", pp. 219-224, ils.

M eierovich, Clara, "En la más honda música de selva, de José Antonio Alcaraz", pp. $225-227$.

Semblanzas

Vargaslugo, Elisa, "D on Federico Sescosse Lejeune (1915-1999). Un hombre, un destino y un lugar...", pp. 229-23I.

García Barragán, Elisa, "Salvador M oreno M anzano (1916-1999)", pp. 233-236.

Resúmenes/Abstracts, pp. 243-246.

Anales del Instituto de Investigaciones Estéticas, vol. XXI, núms. 74-75, primavera-otoño de 1999 .

Bargellini, Clara, "Introducción", pp. 5-9.

Artículos

D aC osta Kaufmann, Thomas, "La geografía artística en América: el legado de Kubler y sus límites", pp. II-27.

Lara, Jaime, "Cristo-H elios americano: la inculturación del culto al sol en el arte y arquitectura de los virreinatos de la N ueva España y del Perú", pp. 29-49, ils.

Cummins, Tom, "On the Colonial Formation of Comparison: The Virgin of Chiquinquirá, The Virgin of G uadalupe and Cloth", pp. 5I-77, ils.

Bargellini, Clara, "La pintura sobre lámina de cobre en los virreinatos de la N ueva España y del Perú", pp. 79-98, ils.

López Pérez, M aría del Pilar, "El objeto de uso en las salas de las casas de habitación de españoles y criollos en Santafé de Bogotá. Siglos XVII y XVIII en el N uevo Reino de G ranada", pp. 99-134, ils.

Goulão, M aria J osé, "A arte da prataria no Brasil e no Rio da Prata no período colonial: estudo comparativo", pp. I35-I45.

Rodríguez $\mathrm{C}$ amilloni, $\mathrm{H}$ umberto, "M anuel de Amat y Junyent y la $\mathrm{N}$ avona de $\mathrm{L} i$ ma: un ejemplo de diseño urbano barroco del siglo XVIII en el virreinato del $\mathrm{Pe}$ rú", pp. I47-176, ils.

T orre Villalpando, Guadalupe de la, "Proyectos urbanísticos para el resguardo de la ciudad de M éxico. Siglo XVIII", pp. I77-193, ils. 
Fajardo de la Rueda, M arta, "La jura del rey Carlos IV en la N ueva Granada", pp. 195-209.

Wilson, Christopher C., "Saint Teresa of Ávila's M artyrdom: Images of H er T ransverberation in M exican Colonial Painting", pp. 2II-233, ils.

D allal, Alberto, "Exploraciones sobre la construcción y la reconstrucción coreográficas", pp. 235-253.

0 bras, documentos, noticias

Zazueta M anjarrez, José C arlos, "H istoria de un monumento que se negó a morir. La iglesia de N uestra Señora del Rosario, El Rosario, Sinaloa", pp. 257-269.

H errera, Arnulfo, "Q uevedo en la N ueva España. Presencia de un conocido texto escatológico de Q uevedo en un impreso mexicano del siglo XVIII", pp. 27I-289.

T erán E., M aría Isabel, "'La heroína mexicana': una novela inédita novohispana del siglo XVIII", pp. 29I-309.

Libros, reseñas

Lara, Ángeles, "Aquella Fénix más rara. Vida de sor Juana I nés de la C ruz, de Alejandro Soriano Vallès", pp. 313-317.

Fernández M artha, "El Primero sueño de sor Juana Inés de la Cruz. Bases tomistas, de Alejandro Soriano V allès", pp. 317-319.

H errera, Arnulfo, "La palabra del poder y el poder de la palabra. Aproximación a las relaciones entre el discurso político y el narrativo, coordinado por Rubén $D$. M edina y José R. Valles C alatrava", pp. 320-324.

Resúmenes/Abstracts, pp. 331-338.

Anales del Instituto de Investigaciones Estéticas, vol. XXII, núm. 76, primavera de 2000.

Artículos

Díaz C ayeros, Patricia, "Pablo de Céspedes entre Italia y España", pp. 5-60, ils.

Cuesta H ernández, Luis J avier, "Sobre el estilo arquitectónico en Claudio de Arciniega. Su participación en la construcción de los conventos agustinos de Acolman, Actopan y M etzitlán. Su papel en la arquitectura novohispana del siglo XVI", pp. 6I-88, ils.

O livares Zorrilla, Rocío, "El libro metágrafo de Alejo de Venegas y El sueño de sor Juana: la lectura del universo", pp. 89-II3.

Aguilar 0 choa, Arturo, "La influencia de los artistas viajeros en la litografía mexicana (1837-I849)", pp. II5-I43, ils.

Arciniega, H ugo, "Los palacios de Themis", pp. I45-I80, ils. 
DOI: http://dx.doi.org/10.22201/iie.18703062e.2000.77.1938

292

ÍNDICES

Bonilla Reyna, H elia Emma, "Joaquín G iménez y El Tío N onilla", pp. I8I-237, ils. Báez M acías, Eduardo, "O tto D ix: serie gráfica sobre la guerra", pp. 239-253, ils.

O bras, documentos, noticias

Vallebueno Garcinava, M iguel, "El señor del M ezquital: un Cristo de caña del siglo XVI en D urango", pp. 257-260, ils.

Lorenzo M acías, José M aría, "U na noticia más sobre Simón Pereyns", pp. 26I-266.

Alcántara Rojas, Berenice, "Breve aclaración sobre el exemplum de Valentín de la Roca", pp. 267-269, ils.

Pérez-Amador Adam, Alberto, "Aportación bibliográfica: los estudios dedicados a Primero sueño de sor J uana Inés de la Cruz en el siglo XX", pp. 27I-286.

Curiel, Gustavo, Juana Gutiérrez y Rogelio Ruiz Gomar, "El Parián", pp. 287-29I.

M ayer, Roberto L., "John Phillips, Alfred Rider. Su álbum M exico Illustrated. ¿Q uié nes fueron los autores de los dibujos originales?", pp. 293-308, ils.

Libros, reseñas

D e la Fuente, Beatriz, "El antiguo 0 ccidente de M éxico. Arte y arqueol ogía de un pasado desconocido, Richard F. Towsend, editor general, y Carlos Eduardo Gutiérrez, editor en español", pp. 3II-3I5.

M erril, William, "N ómadas y sedentarios en el N orte de M éxico: homenaje a Beatriz Braniff, M arie-Areti H ers, José Luis M irafuente et al., compiladores", pp. 3i6319.

O livares Zorrilla, Rocío, "El Primero sueño de sor Juana Inés de la Cruz. Bases tomistas, de Alejandro Soriano Vallès", pp. 319-325.

Zepeda, Jorge, "L os gremios de plater os y de batihojas en la ciudad de Q uito (s glo XVII), de G loria Garzón M ontenegro y Jesús Paniagua Pérez", pp. 326-328.

Ramírez, Fausto, "El imaginario de Luis M árquez", en Alquimia, pp. 328-332.

Krieger, Peter, "La an-estética de la arquitectura, de N eil Leach", pp. 332-336.

Semblanzas

N oelle, Louise, "Xavier M oyssén", pp. 337-340, ils.

Krieger, Peter, "Ianis Xenakis", pp. 34I-342.

Resúmenes/Abstracts, pp. 347. 